\title{
Bisphosphonate Therapy and Tooth Development in Children and Adolescents with Osteogenesis Imperfecta
}

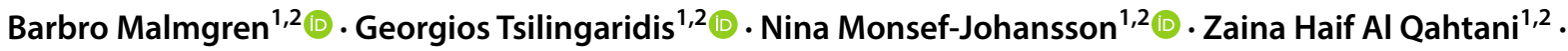 \\ Göran Dahllöf ${ }^{1,2}$ (1) . Eva Åström ${ }^{3,4}$ (B)
}

Received: 1 April 2020 / Accepted: 13 May 2020 / Published online: 25 May 2020

(c) The Author(s) 2020

\begin{abstract}
Osteogenesis imperfecta (OI) is a heterogeneous connective tissue disorder characterized by repeated fractures and skeletal disorders. At present, bisphosphonate (BP) therapy is the gold standard for OI treatment. The present retrospective study evaluated the effect of BP therapy on tooth development and eruption of permanent teeth in a cohort of children receiving pamidronate. Three groups were studied: patients with OI who were treated with BPs $(n=45)$, patients with OI who were not treated with BPs $(n=117)$, and age- and gender-matched healthy controls $(n=121)$. Dental age, dental maturity, and tooth eruption were assessed on panoramic radiographs using the methods of Demirjian et al. (Hum Biol 45(2):211-227, 1973) and Haavikko (Suom Hammaslaak Toim 66(3):103-170, 1970) and were evaluated using the $t$-test, Chi-square test, and the Mann-Whitney $U$ test. Dental age in the study group was significantly $(p<0.05)$ lower than chronological age compared with both control groups. Dental maturity and the eruption of permanent teeth were also significantly $(p<0.05)$ delayed in the study group in relation to the two control groups. The dental age was significantly lower $(p<0.001)$ in patients with OI type III treated with BPs compared with healthy controls and the dental maturation was significantly delayed in patients with OI type IV treated with BPs compared with those not treated. In conclusion, BP therapy in OI patients seems to lower the dental age, delay the dental maturity, and tooth eruption. BP administration before 2 years of age might be a contributing factor.
\end{abstract}

Keywords Bisphosphonate $\cdot$ Osteogenesis imperfecta $\cdot$ Tooth development $\cdot$ Bone resorption $\cdot$ Dental age $\cdot$ Root resorption

\section{Introduction}

Osteogenesis imperfecta (OI) is a heterogeneous connective tissue disorder [1].The disease is usually inherited in an autosomal dominant manner, although new mutations are common. In $85-90 \%$ of the cases, the mutations are located in the COL1A1 and COL1A2 genes in chromosomes 17 and 7, respectively [2]. In recent years, several other genes have

Barbro Malmgren

barbro.malmgren@ki.se

1 Department of Dental Medicine, Division of Orthodontics and Pediatric Dentistry, Karolinska Institutet, Huddinge, Sweden

2 Center for Pediatric Oral Health Research, Stockholm, Sweden

3 Department of Woman and Child Health, Karolinska Institutet, Stockholm, Sweden

4 Pediatric Neurology, Astrid Lindgren Children's Hospital at Karolinska University Hospital, Stockholm, Sweden been associated with the disease [3], and there are now more than 1500 known mutations in over 20 different genes. New mutations are being detected and reported over time, and their effects on tissue structure and biomechanics studied [4-6]. The clinical manifestations may include bone fragility, skeletal deformities, growth and hearing deficiencies, joint instability due to laxity of ligaments, coagulation and bleeding disturbances, skeletal pain, blue sclerae, dentinogenesis imperfecta (DGI), and other dental development disorders $[2,3,5,7-10]$, of which tooth agenesis is the most frequent [11]. The most commonly used classification of OI is based on clinical, radiological, and hereditary findings: type I (mild OI with blue sclera), type II (pre- or perinatal lethal), type III (severely deforming), and type IV (variable but often moderate severity, and white sclerae after infancy) [10].

The core feature of OI therapy is fracture prevention. Treatment with bisphosphonates (BPs) is today the gold standard treatment for children with OI [12]. Alendronate, risedronate, pamidronate, and zoledronate are today the most 
commonly bisphosphonates used for treatment in individuals with OI although in children intravenous pamidronate or zoledronate are most frequently used. They act mainly by inhibiting osteoclast function. Intravenous BPs have proven to decrease bone pain and improve muscle strength and mobility. It increases cortical thickness, vertebral size and architecture and bone mineral density and thereby decreased fracture incidence [13-17]. Treatment with pamidronate infusions started 1991 in Sweden and it was initially given to adolescents with severe OI but later also to younger children with the more severe phenotypes of OI, types III and IV. Later on, it was also given to individuals with milder phenotype but with vertebral compressions, repeated bone fractures, and pain. Before 1991 treatment with physiotherapy, orthotics, orthopedic surgery, and intravenous calcitonin were the only available treatment options [14].

Tooth eruption involves bone resorption and deposition [18], and it is well known that osteoclasts are important for tooth eruption and for resorption of the primary teeth [19]. Two human studies $[20,21]$ on how BP therapy affects tooth development reported conflicting results. Kamoun-Goldrat et al. [20] claimed that the therapy was associated with delayed tooth eruption, while Vourimies et al. [21] found age-appropriate dental development.

The present study evaluated the effect of BP therapy on the maturation and eruption of permanent teeth in a cohort of 45 children and adolescents with OI, whose ages ranged from newborn to 12 years at the start of therapy, and who had undergone treatment for at least 1 year. Healthy children and adolescents and children and adolescents with OI who had not had treatment with BPs acted as controls. The hypotheses were that BP treatment delays dental maturity, dental age, and tooth eruption when treatment begins in early childhood.

\section{Methods}

\section{Subjects}

All participants with OI had received care at Astrid Lindgren Children's Hospital from the national multidisciplinary pediatric OI team at Karolinska University Hospital in Stockholm between 1991 and 2018. Fifty-three children and adolescents with OI ( 26 boys and 27 girls) treated with BPs and 121 children with OI (76 boys and 46 girls) who had not been treated with BPs were identified. The 126 healthy age- and gender-matched children and adolescents had been patients at the Department of Pediatric Dentistry at Karolinska Institutet. All OI patients and healthy controls who were under age 16 years at the time of their radiographic examination were included. Excluded were individuals who were missing both lower second premolars: two boys and six girls with OI treated with BPs, four boys and one girl with OI not treated with BPs, and five healthy controls (three boys and two girls). Of the excluded children treated with BPs, both boys and five of the six girls had begun BP treatment before 2 years of age.

The included participants formed three groups: those with OI who had been treated with BPs (the study group); those with OI who had not been treated with BPs (control group 1); and healthy, matched controls (control group 2).

The study group consisted of 45 children and adolescents with OI, 24 boys and 21 girls treated with BPs for at least 1 year. In 14 children, seven boys and seven girls, BP therapy was begun before the age of 2 years. Data extracted from existing dental and medical records included panoramic radiographs, medication, and type of OI. Nineteen children presented with OI type I, 12 with OI type III, and 14 with OI type IV. The mean age at radiographic evaluation was 10.1 years (5.7-15.0). In 30 subjects, BP therapy started before 6 years of age and in 14 from 6 up to 12 years. Only one individual had started BP therapy after 12 years. The gender distribution was equal with 16 boys and 14 girls in the first group, and seven boys and seven girls in second.

The extracted data on BP therapy included doses, duration, and cumulative dose. Mean age at treatment start was 3.9 years $(0.2-13.0)$ The infusions were initially given monthly in doses of $10-30(40) \mathrm{mg} / \mathrm{m}^{2}$ pamidronate during $5-8 \mathrm{~h}$ preceded by hydration with $25 \mathrm{mg} / \mathrm{ml}$ of buffered glucose (total dose of $500 \mathrm{ml} / \mathrm{m}^{2}$ for $2-4 \mathrm{~h}$ ). For the first 3 months, a dose of $10 \mathrm{mg} / \mathrm{m}^{2}$ was given, over the next 3 months $20 \mathrm{mg} / \mathrm{m}^{2}$, followed by $30 \mathrm{mg} / \mathrm{m}^{2}$ for further treatment. After these first 6 months, a few patients received a dose of $40 \mathrm{mg} / \mathrm{m}^{2}$. Treatment time was later shortened to $4 \mathrm{~h}$ without pre-treatment hydration. After normalization of bone mineral density, treatment intervals were individualized, successively increasing to once every 2-6 months depending on bone density values and pain.

Control Group 1 included 117 children with OI, 72 boys and 45 girls who had not been treated with BPs. Data were extracted from existing dental and medical records including panoramic radiographs, medication, and type of OI. Ninetysix children presented with OI type I, 2 with OI type III, and 19 with OI type IV. Children and adolescents with severe forms of OI born before BPs were introduced as a therapy was included in this group.

Control Group 2 consisted of 121 randomly selected healthy age- and gender-matched children and adolescents, 55 boys and 66 girls, from the Department of Pediatric Dentistry at Karolinska Institutet. Data were extracted from existing panoramic radiographs taken between 2016 and 2018. Inclusion criteria were healthy children aged $4-16$ years. 
Table 1 Group characteristics of the children and adolescents with osteogenesis imperfecta (OI), with and without bisphosphonate (BP) treatment, and healthy age- and gender-matched controls

\begin{tabular}{|c|c|c|c|c|}
\hline & OI type I & OI type III & OI type IV & Total \\
\hline \multicolumn{5}{|c|}{ Study group: with OI, BP treatment } \\
\hline Number of subjects & 19 & 12 & 14 & 45 \\
\hline Gender $(\mathrm{M} / \mathrm{F})$ & $11 / 8$ & $4 / 8$ & $9 / 5$ & $24 / 21$ \\
\hline DGI (yes/no) & $4 / 15$ & $5 / 7$ & $5 / 9$ & $14 / 31$ \\
\hline Age at imaging & $10.5(6.0-15.0)$ & $9.6(5.7-13,8)$ & $9.8(7.6-14.1)$ & $10.1(5.7-15.0)$ \\
\hline Age at treatment onset & $5.4(0.25-10.4)$ & $1.9(0.3-7.1)$ & $4.9(0.2-12.5)$ & $3.5(0.2-12.5)$ \\
\hline Treatment, years $^{\mathrm{a}}$ & $5.2(0.9-13.0)$ & $7.7(4.3-12.8)$ & $5.1(1.0-11.0)$ & $5.8(1.0-13.0)$ \\
\hline Cumulative BP dose $\left(\mathrm{mg} / \mathrm{m}^{2}\right)$ & 1097 (260-2180) & $1333(710-2730)$ & $1138(240-3850)$ & $1189(240-3850)$ \\
\hline \multicolumn{5}{|c|}{ Control group 1: with OI, no BP treatment } \\
\hline Number of subjects & 96 & 2 & 19 & 117 \\
\hline Gender $(\mathrm{M} / \mathrm{F})$ & $59 / 37$ & $1 / 1$ & $12 / 7$ & $72 / 45$ \\
\hline DGI (yes/no) & $8 / 88$ & $2 / 0$ & $7 / 12$ & $16 / 101$ \\
\hline Age at imaging & $9.4(4.1-15-8)$ & $11.6(10.1-13.1)$ & $9.1(6.3-14.2)$ & $9.4(4.3-15.8)$ \\
\hline \multicolumn{5}{|c|}{ Control group 2: Healthy controls } \\
\hline Number of subjects & & & & 121 \\
\hline Gender $(\mathrm{M} / \mathrm{F})$ & & & & $55 / 66$ \\
\hline DGI (yes/no) & & & & - \\
\hline Age at imaging & & & & $8.6(4.2-15.4)$ \\
\hline
\end{tabular}

${ }^{\mathrm{a}}$ From treatment onset to study start

DGI Dentinogenesis imperfecta

Table 1 describes the characteristics of the study group and the two control groups.

The regional ethics committee in Stockholm approved the study protocol (Daybook no. 157/99 and 2014/254-31/4).

\section{Radiographic Analyses}

Conventional screen-film $(n=57)$ or digital panoramic radiographs $(n=226)$ from the dental records of all study participants were analyzed regarding permanent tooth development and number of erupted permanent teeth. The radiographs were anonymized, coded, and analyzed under standardized terms. A Mattsson's binocular and a light table were used to assess the screen-film radiographs.

Two observers, NMJ and ZHQ, evaluated all radiographs from the three groups separately. BM and GT made a second determination independently. When more than one panoramic radiograph was available, the one with the best quality taken at age 9-10 years was chosen. When the scores differed, one of the two dentists (BM or GT) re-evaluated the radiograph.

Dental age and dental maturity were assessed by evaluating the mineralization stages of the seven mandibular teeth on the left side. The mineralization stages ranged from beginning of crown calcification to a completely closed root apex, as described by Demirjian et al. [22]. Each tooth was divided into eight formative stages (A to $\mathrm{H}$ ), and each stage was allocated a score depending on the gender. If an assessment was between two stages, the earlier stage was selected [22]. If a tooth was missing, the contralateral tooth was analyzed.

The stages were converted to dental maturity scores and summarized. A maturity score was then derived from the addition of the scores of all seven teeth. This maturity score was converted directly into a dental age by using a pre-constructed table and the difference between the chronological and dental age was calculated.

Permanent tooth eruption was assessed for each patient. If the primary tooth was missing or had been extracted before expected exfoliation due to caries or infection, the contralateral tooth was analyzed. A tooth was recorded as erupted if it had penetrated the marginal bone level. We used the reference values for timing of tooth eruption from the Haavikko study on healthy Finnish children [23].

\section{Statistical Analysis}

Between-group comparisons of dental scores, cumulative doses, and impact of DGI on eruption were done with the Mann-Whitney $U$ test. The $t$-test assessed differences between chronological age and estimated dental age. Chisquare test was used to evaluate the number of erupted permanent teeth in each group compared with reported normal values [24]. All comparisons were made both according to 
gender and pooled. The level of significance was set at 5\%. No comparisons could be made separately for the group "OI type III not treated with BP" since there were only 2 individuals.

We randomly selected 29 patients from the entire study sample to evaluate precision in estimating dental age according to Demirjian [22], and the number of erupted teeth with double determination according to the reference values of Haavikko [23]. Kappa values were used for inter-observer agreement. For dental scores, agreement was $90 \%(\kappa=0.80)$, and for eruption, $86 \%(\kappa=0.72)$, indicating a strong level of agreement.

All data were analyzed with Statistica v. 13 (StatSoft; Scandinavia AB, Uppsala, Sweden).

\section{Results}

\section{Severity of 이}

The cumulative BP dose was significantly higher in patients with OI type III compared with OI type I $(p=0.011)$ and IV $(p=0.014)$. There was no difference in doses between OI types I and IV.

The dental age was significantly lower in patients with OI type III treated with BPs compared with the healthy controls $(p<0.001)$, and dental maturity was significantly delayed in patients with OI type III $(p<0.001)$ and OI type IV $(p=0.024)$ treated with BP compared with the two control groups. No difference was found between boys and girls.

In patients with OI type I treated with BPs, the eruption was significantly $(p=0.034)$ earlier compared with healthy controls. The variation in number of erupted teeth was higher in the healthy controls $(-2$ to +4$)$ than in OI type I $(-1.0$ to +2$)$. No difference was found between boys and girls.

We found that the cumulative dose of BPs was significantly higher in patients were BP therapy started before 6 years of age compared with those starting the BP therapy from 6 up to 12 years $(p<0.001)$. Despite the higher cumulative dose in patients $<6$ years of age, no differences in dental age, dental maturation or in eruption were found.

\section{Dental Age/Dental Maturity}

Estimated dental age was significantly lower than chronological age in the study group compared to the two control groups: those not treated with BPs $(p=0.036)$ and the healthy controls $(p=0.032)$. Differences between the two control groups were not significant; neither were differences

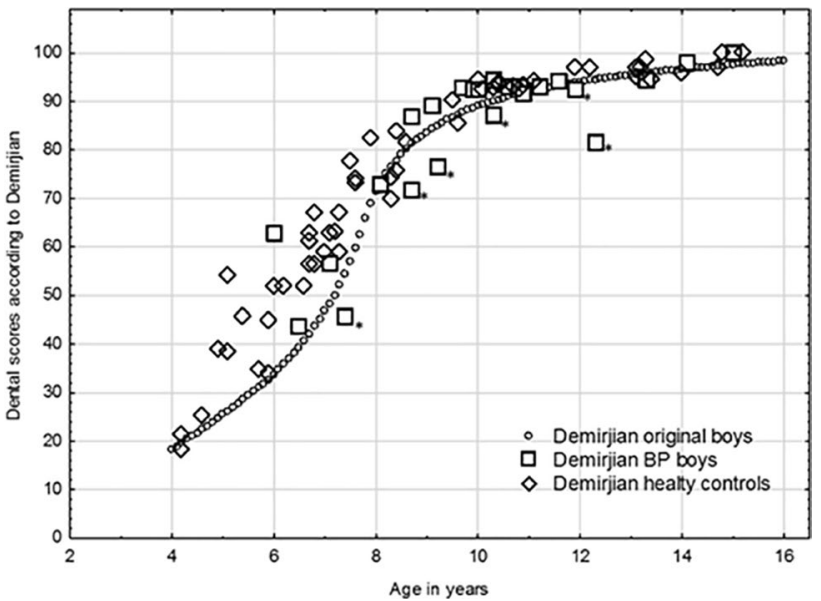

Fig. 1 A scatterplot showing the dental scores according to Demirjian for 24 boys treated with BPs and 55 healthy controls. *Boys treated with BPs with a cumulative dose greater than $1000 \mathrm{mg} / \mathrm{m}^{2}$. BPs bisphosphonates

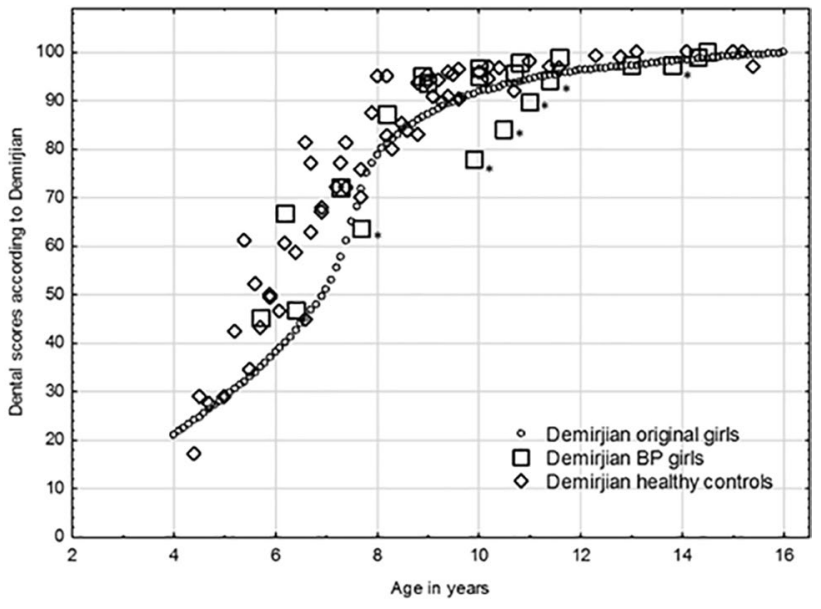

Fig. 2 A scatterplot showing the dental scores according to Demirjian for 21 girls treated with BPs and 66 healthy controls. *Girls treated with BPs with a cumulative dose greater than $1000 \mathrm{mg} / \mathrm{m}^{2} . B P s$ bisphosphonates

between individuals with and without DGI nor between boys and girls.

Dental maturity was significantly delayed in the study group compared with those not treated $(p=0.004)$ and to healthy controls $(p=0.002)$. Dental maturity was significantly delayed in boys with OI who had been treated with BPs compared with those who had not $(p=0.021)$, and also compared with healthy controls $(p=0.012)$. Differences similar to those for boys existed among girls, but the differences were not significant; between the study group and the OI group that had not been treated with BPs $(p=0.075)$, and between the study group and the healthy controls ( $p=0.099$; Figs. 1 and 2). Differences between 
the two control groups for both genders were non-significant $(p=0.917)$.

\section{Eruption}

Eruption was significantly delayed in children with OI who had been treated with BPs, compared with those who had not $(p=0.001)$ and healthy controls $(p=0.008)$. Among boys with OI, eruption was significantly delayed in those who had been treated with BPs compared with those who had not $(p=0.037)$ and healthy controls $(p=0.030$; Fig. 3). No significant difference was found in girls with OI who had been treated with BPs compared with those who had not $(p=0.547)$ and healthy control $(p=0.428)$. The average delay in boys was 1.5 years $(-0.1$ to +4.0$)$, and in girls, 0.8 years $(0$ to +3.4$)$. No significant difference was found between the two control groups. There was no difference in number of erupted teeth in patients with and without DGI.

Dentinogenesis Imperfecta (DGI) was found in $21 \%$ of the patients with OI type I treated with BP and in $8 \%$ in those not. The gender distribution was equal. In patients with OI type III/IV, DGI was found in $38 \%$ of the patients both for those treated with BPs and for those not. Boys were more affected than girls.
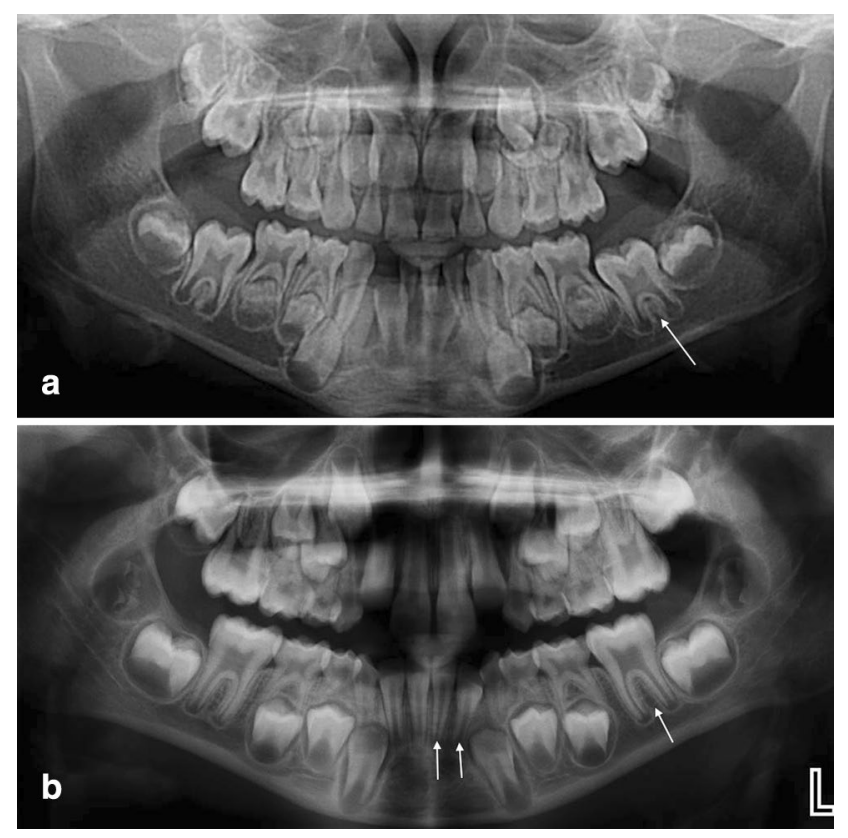

Fig. 3 Two boys at 7.4 years of age. a treated with BP since the age 0.3 years, Demirjian dental score 45.6. Only the permanent lower left molar in the left mandibular quadrant erupted. b healthy control, Demirjian dental score 77.7. Three permanent teeth fully erupted in the left lower side. $B P$ bisphosphonate

\section{Discussion}

The main findings in the present study are that the dental age and dental maturity of individuals treated with BPs are significantly lower when compared to patients with OI who had not been treated with BPs and healthy controls. Furthermore, tooth eruption was significantly delayed in children treated with BPs. In both control groups, maturity was accelerated in correlation with Demirjian's dental scores [22]; but in contrast to Vuorimies et al. [21], we found no difference in dental maturity between the two control groups. When analyzing the different types of OI, we found that the dental maturation was significantly delayed in patients with OI types III and IV compared with healthy controls.

The system used to assess dental age in this study was the worldwide used assessment system of Demirjian et al. [22]. In many countries, dental maturity of Caucasian children has been found to be earlier than in the Demirjian assessment system [25-29], and dental age might be overestimated [30]. In 1998, a report described a trend towards earlier dental maturation in orthodontic patients between the 1970s and 1990s [31]. Another study showed that root maturation in children in a modern sample was advanced compared with children in a historic sample of 50 years before [32]. Jääsaari et al. [33] found that dental maturity of Finnish 6-12-year-old children was advanced by $0.6-1.0$ years compared with chronological age and suggested that the advancement in dental maturity might be associated with higher energy intake. Earlier puberty has also been observed in girls and boys over the last century. The reasons for these changes are unknown but may be explained by environmental and social factors [34]. Genetic, hormonal, and environmental interactions as well as epigenetic and nutritional factors may also be involved in dental development.

We found that individuals treated with BPs demonstrated a significantly lower dental age and dental maturity when compared with OI patients not treated with BPs and healthy controls. This is in contrast to Vourimies et al. [21], who found no significance difference between chronological and dental age in their study group (only five subjects had been treated with BPs before the age of 2 years). One explanation for our results might be the higher number of children below 2 years of age who had been treated with BPs in the present study.

At present, the nitrogen-containing BPs pamidronate and zoledronate are the most commonly used for intravenous medication of children with OI. They have different in vitro potencies, with pamidronate having the lowest relative potency of 100 , and zoledronic acid, the highest with a relative potency 10,000 . In our study, only intravenous 
pamidronate was administrated. In the two human studies of Kamoun-Goldrat et al. [20] and Vourimies et al. [21], the age of the population, medical treatment, evaluation methods, and results differed. The ages of the 33 children and adolescents in the Kamoun-Goldrat et al. study [20] ranged from 6.2 to 14.6 years at the start of BP therapy; the researchers did not report which BP was being used. The ages of the 22 children and adolescents in the Vourimies et al. study [21] ranged from 0.1 to 13.0 years at the start of therapy; this research group used various types of BPs such as intravenous pamidronate and zoledronic acid, and oral administration of risedronate.

Resorption of the roots of primary teeth is needed for a permanent tooth to erupt. For that process to be possible, alveolar bone resorption must occur and a biological process for the tooth to move in the pathway must be possible [19]. BPs act by inhibiting osteoclast function and thereby decrease bone resorption. This effect on bone density persists for years since the half-life of BPs is a decade [2]. Since tooth eruption involves bone resorption and deposition [18, 35], osteoclasts are important for tooth eruption and for resorption of primary teeth [19]. BP-induced decreases in osteoclast activity may affect tooth development. We assessed eruption based on the results of Haavikko [23] because we used the same criteria for eruption in the panoramic radiographs. This study was published as early as 1970. Parner et al. [36] concluded that the emergence of permanent teeth was not subject to acceleration between 1969 and 1996 and, consequently, the study by Haavikko is still relevant. Parner et al. recorded a tooth as erupted when any part of it had emerged through the gingiva. Vuorimies et al. [21] related the number of erupted teeth to the study by Nyström et al. [37]. In their study, they recorded a tooth as erupted when any part of it had emerged through the gingiva while Vourimies et al. [21] recorded it as erupted also when it had radiographically pierced the alveolar bone, which makes a correlation unsure. In the present study, we demonstrate a significantly delayed tooth eruption in children with OI who had been treated with BPs compared with those who had not and healthy controls. We also found a significantly delayed tooth eruption among boys with OI treated with BP, compared the two control groups, which was not seen among girls.

Regarding eruption, Kamoun-Goldrat et al. [20] examined their subjects only by visual inspection of all four quadrants and the number of delayed teeth was determined using the classical data of Hurme [41] where a tooth was described as delayed if it had not emerged in the age range given by Hurme. Although they did not report type of OI, we assume that the majority had OI type III as they had been treated with BPs. We reported earlier [11] that tooth agenesis occurs more often in OI type III-affected individuals, $47 \%$, compared with OI types I (12\%) and IV (13\%). Thus, as
Vuorimies et al. [21] also discussed, the effect on tooth eruption in patients who had received BP therapy is likely overestimated. Vourimies et al. studied only the left mandibular teeth and used as reference values published norms for the timing of tooth eruption [37]. Our results differed from the results reported by Vourimies et al. One explanation might the higher number of individuals in all groups in our study. Furthermore, 14 children in the present study had started BP therapy before the age of 2 years compared to five in the former (personal communication).

The prevalence of DGI in OI type I varies from 8 to $40 \%$ $[7,8,38-40]$. In the present study, DGI was found in $10 \%$ and it was more frequent in children treated with BPs (21\%), than in those not treated (8\%). Normally, DGI is less frequent in patients with OI type I compared with patients with OI type III/IV which is also demonstrated in the present study. The difference seen in patients with OI type I treated with BP compared with those not treated is most probably just a coincidence. Hypothetically, as teeth affected with DGI have more calcified tissue to be resorbed, this could delay tooth eruption. We found no difference in eruption between teeth with and without DGI.

Surprisingly, the eruption was significantly delayed in the healthy controls compared with the patients with OI type I treated with BPs. The high variation in number of erupted teeth in the healthy controls was probably a contributing factor. We found a delay in dental maturation in children treated before two years of age (Figs. 1 and 2) and as only three children with OI type I started BPs therapy before 2 years of age, the BP therapy was not reflected here.

In conclusion, BP therapy in OI patients seems to lower the dental age, and delay the dental maturity and tooth eruption. BP administration before 2 years of age might be a contributing factor.

\section{Limitations}

In some cases, assessment of dental maturity was difficult due to either image quality or overlapping contours. Another limitation was the position of the cervical spine, which sometimes obscured the incisors in the radiographs, making these teeth difficult to assess. Unfortunately, the images were not taken under standardized conditions since the radiographs had been made using either screen-film or digital sensors in different clinics around Sweden over 27 years.

Acknowledgments Open access funding provided by Karolinska Institute.

Author Contributions BM conceptualized and designed the study, performed radiographic dental examinations of the patients, performed statistical analyses, analyzed and interpreted the data, and drafted the manuscript. GT conceptualized and designed the study, performed radiographic dental examinations of the patients, analyzed and interpreted 
the data, and drafted the manuscript. NMJ performed radiographic dental examinations of the patients, took part in analysis and interpretation of data, and drafted the manuscript. ZHQ performed radiographic dental examinations of the patients and took part in analysis and interpretation of data. GD analyzed and interpreted the data and drafted the manuscript. EA conceptualized and designed the study and drafted the manuscript, was responsible for clinical medical examination and data collection, and participated actively in data analysis. All authors revised the paper critically for intellectual content and approved the final version. All authors agree to be accountable for the work and to ensure that any questions relating to the accuracy and integrity of the paper are investigated and properly resolved.

Funding This study was funded by grants from Stiftelsen Olle Engkvist Byggmästare (Grant Number: 191-449) to B.M. and from Stiftelsen Sunnerdahls Handikappfond (Grant Number: $35 / 18$ ) to E. A.

\section{Compliance with Ethical Standards}

Conflict of interest Barbro Malmgren, Georgios Tsilingaridis, Nina Monsef-Johansson, Zaina Haif Al Qahtani, Göran Dahllöf, and Eva Åström declare that they have no conflicts of interest.

Ethical Approval All procedures performed in the study involving human participants were in accordance with the ethical standards of the National Research committee and with the 1964 Helsinki Declaration and its later amendments or comparable ethical standards.

Informed Consent Informed consent was obtained from all participants in the present study.

Open Access This article is licensed under a Creative Commons Attribution 4.0 International License, which permits use, sharing, adaptation, distribution and reproduction in any medium or format, as long as you give appropriate credit to the original author(s) and the source, provide a link to the Creative Commons licence, and indicate if changes were made. The images or other third party material in this article are included in the article's Creative Commons licence, unless indicated otherwise in a credit line to the material. If material is not included in the article's Creative Commons licence and your intended use is not permitted by statutory regulation or exceeds the permitted use, you will need to obtain permission directly from the copyright holder. To view a copy of this licence, visit http://creativecommons.org/licenses/by/4.0/.

\section{References}

1. Marini J, Smith SM (2015) Endotext [Internet]. South Dartmouth (MA): MDText.com, Inc.; 2000-2015 Apr 22

2. Forlino A, Marini JC (2016) Osteogenesis imperfecta. Lancet 387(10028):1657-1671

3. Biggin A, Munns CF (2014) Osteogenesis imperfecta: diagnosis and treatment. Curr Osteoporos Rep 12(3):279-288

4. Li L, Zhao D, Zheng W, Wang O, Jiang Y, Xia W, Xing X, Li M (2019) A novel missense mutation in P4HB causes mild osteogenesis imperfecta. Biosci Rep 39(4):BSR20182118

5. Marini JC, Forlino A, Bachinger HP, Bishop NJ, Byers PH, Paepe A, Fassier F, Fratzl-Zelman N, Kozloff KM, Krakow D et al (2017) Osteogenesis imperfecta. Nat Rev Dis Primers 3:17052

6. Nijhuis WH, Eastwood DM, Allgrove J, Hvid I, Weinans HH, Bank RA, Sakkers RJ (2019) Current concepts in osteogenesis imperfecta: bone structure, biomechanics and medical management. J Child Orthop 13(1):1-11

7. Andersson K, Dahllöf G, Lindahl K, Kindmark A, Grigelioniene G, Åström E, Malmgren B (2017) Mutations in COL1A1 and COL1A2 and dental aberrations in children and adolescents with osteogenesis imperfecta-A retrospective cohort study. PLoS ONE 12(5): $\mathrm{e} 0176466$

8. Malmgren B, Norgren S (2002) Dental aberrations in children and adolescents with osteogenesis imperfecta. Acta Odontol Scand 60(2):65-71

9. O'Connell AC, Marini JC (1999) Evaluation of oral problems in an osteogenesis imperfecta population. Oral Surg Oral Med Oral Pathol Oral Radiol Endod 87(2):189-196

10. Sillence DO, Senn A, Danks DM (1979) Genetic heterogeneity in osteogenesis imperfecta. J Med Genet 16(2):101-116

11. Malmgren B, Andersson K, Lindahl K, Kindmark A, Grigelioniene G, Zachariadis V, Dahllöf G, Aström E (2017) Tooth agenesis in osteogenesis imperfecta related to mutations in the collagen type I genes. Oral Dis 23(1):42-49

12. Dwan K, Phillipi CA, Steiner RD, Basel D (2014) Bisphosphonate therapy for osteogenesis imperfecta. Cochrane Database Syst Rev 7:CD005088

13. Åström E, Jorulf H, Söderhäll S (2007) Intravenous pamidronate treatment of infants with severe osteogenesis imperfecta. Arch Dis Child 92(4):332-338

14. Åström E, Söderhäll S (1998) Beneficial effect of bisphosphonate during five years of treatment of severe osteogenesis imperfecta. Acta Paediatr 87(1):64-68

15. Åström E, Söderhäll S (2002) Beneficial effect of long term intravenous bisphosphonate treatment of osteogenesis imperfecta. Arch Dis Child 86(5):356-364

16. Lindahl K, Kindmark A, Rubin CJ, Malmgren B, Grigelioniene G, Söderhäll S, Ljunggren O, Åström E (2016) Decreased fracture rate, pharmacogenetics and BMD response in 79 Swedish children with osteogenesis imperfecta types I, III and IV treated with Pamidronate. Bone 87:11-18

17. Shi CG, Zhang Y, Yuan W (2016) Efficacy of bisphosphonates on bone mineral density and fracture rate in patients with Osteogenesis Imperfecta: a systematic review and meta-analysis. Am J Ther 23(3):e894-904

18. Marks SC Jr, Schroeder HE (1996) Tooth eruption: theories and facts. Anat Rec 245(2):374-393

19. Wise GE (2009) Cellular and molecular basis of tooth eruption. Orthod Craniofac Res 12(2):67-73

20. Kamoun-Goldrat A, Ginisty D, Le Merrer M (2008) Effects of bisphosphonates on tooth eruption in children with osteogenesis imperfecta. Eur J Oral Sci 116(3):195-198

21. Vuorimies I, Arponen H, Valta H, Tiesalo O, Ekholm M, Ranta H, Evalahti M, Makitie O, Waltimo-Siren J (2017) Timing of dental development in osteogenesis imperfecta patients with and without bisphosphonate treatment. Bone 94:29-33

22. Demirjian A, Goldstein H, Tanner JM (1973) A new system of dental age assessment. Hum Biol 45(2):211-227

23. Haavikko K (1970) The formation and the alveolar and clinical eruption of the permanent teeth. An orthopantomographic study. Suom Hammaslaak Toim 66(3):103-170

24. Landis JR, Koch GG (1977) The measurement of observer agreement for categorical data. Biometrics 33(1):159-174

25. Leurs IH, Wattel E, Aartman IH, Etty E, Prahl-Andersen B (2005) Dental age in Dutch children. Eur J Orthod 27(3):309-314

26. Mörnstad H, Reventlid M, Teivens A (1995) The validity of four methods for age determination by teeth in Swedish children: a multicentre study. Swed Dent J 19(4):121-130 
27. Nykanen R, Espeland L, Kvaal SI, Krogstad O (1998) Validity of the Demirjian method for dental age estimation when applied to Norwegian children. Acta Odontol Scand 56(4):238-244

28. Nyström M, Haataja J, Kataja M, Evalahti M, Peck L, KleemolaKujala E (1986) Dental maturity in Finnish children, estimated from the development of seven permanent mandibular teeth. Acta Odontol Scand 44(4):193-198

29. Wolf TG, Briseno-Marroquin B, Callaway A, Patyna M, Muller VT, Willershausen I, Ehlers V, Willershausen B (2016) Dental age assessment in 6- to 14-year old German children: comparison of Cameriere and Demirjian methods. BMC Oral Health 16(1):120

30. Teivens A, Mörnstad H (2001) A comparison between dental maturity rate in the Swedish and Korean populations using a modified Demirjian method. J Forensic Odontostomatol 19(2):31-35

31. Nadler GL (1998) Earlier dental maturation: fact or fiction? Angle Orthod 68(6):535-538

32. Cardoso HF, Heuze Y, Julio P (2010) Secular change in the timing of dental root maturation in Portuguese boys and girls. Am J Hum Biol 22(6):791-800

33. Jääsaari P, Tolvanen M, Niinikoski H, Karjalainen S (2016) Advanced dental maturity of Finnish 6- to 12-yr-old children is associated with high energy intake. Eur J Oral Sci 124(5):465-471

34. Brix N, Ernst A, Lauridsen LLB, Parner E, Stovring H, Olsen J, Henriksen TB, Ramlau-Hansen CH (2019) Timing of puberty in boys and girls: a population-based study. Paediatr Perinat Epidemiol 33(1):70-78
35. Wise GE (1998) The biology of tooth eruption. J Dent Res 77(8):1576-1579

36. Parner ET, Heidmann JM, Vaeth M, Poulsen S (2001) A longitudinal study of time trends in the eruption of permanent teeth in Danish children. Arch Oral Biol 46(5):425-431

37. Nyström M, Kleemola-Kujala E, Evalahti M, Peck L, Kataja M (2001) Emergence of permanent teeth and dental age in a series of Finns. Acta Odontol Scand 59(2):49-56

38. Lukinmaa PL, Ranta H, Ranta K, Kaitila I, Hietanen J (1987) Dental findings in osteogenesis imperfecta: II. Dysplastic and other developmental defects. J Craniofac Genet Dev Biol 7(2):127-135

39. Lund AM, Jensen BL, Nielsen LA, Skovby F (1998) Dental manifestations of osteogenesis imperfecta and abnormalities of collagen I metabolism. J Craniofac Genet Dev Biol 18(1):30-37

40. Schwartz S, Tsipouras P (1984) Oral findings in osteogenesis imperfecta. Oral Surg Oral Med Oral Pathol 57(2):161-167

41. Hurme VO (1949) Ranges of normalcy in the eruption of permanent teeth. J Dent Child 16(2):11-15

Publisher's Note Springer Nature remains neutral with regard to jurisdictional claims in published maps and institutional affiliations. 